\title{
PARA UNA RELACIÓN PROTEICA: LITERATURA Y FILOSOFÍA
}

\section{A PROTEAN RELATIONSHIP: LITERATURE AND PHILOSOPHY}

\section{Mauro JIMÉNEZ}

Universidad Autónoma de Madrid

$\mathbf{I}$ Juan de Mairena, en uno de sus asertos explicativos, se dirige a sus estudiantes refiriendo una lección aprendida de su maestro, Abel Martín, en torno a la poética y a la filosofía: "-Hay hombres, decía mi maestro, que van de la poética a la filosofía; otros que van de la filosofía a la poética. Lo inevitable es ir de lo uno a lo otro, en esto, como en todo" (Machado, 2003, p. 195). Este ir y venir entre la literatura y la filosofía que señalaba Antonio Machado con la ayuda de sus apócrifos es lo que proponemos en este monográfico. El análisis crítico y también el merodeo ensayístico son la naturaleza de los diez trabajos que presentamos como posibles sendas para pensar una relación proteica e inevitable.

Proteo, nos cuenta la mitología griega, era el anciano rey del mar que poseía dones proféticos y cuya forma era capaz de modificar según fuera necesario pasar desapercibido o, por el contrario, servir como señal de una importante información, tal y como vierte Homero en su Odisea (Graves, 2009, p. 145). Y proteica es la relación que a lo largo de la historia hallamos entre la filosofía y la literatura porque se trata de un vínculo cambiante que desvela unos comunes intereses explicitados con variación. Esta transformación se debe, entre otras cosas, por la propia modificación secular de ambas escrituras. Fuera de los esencialismos reductores, lo humano busca respuestas para las grandes preguntas del ser al tiempo que imagina posibilidades de existencia en la literatura y en la filosofía, pero ambas metamorfosean no solo su estilo sino también su dirección según las inclemencias del cielo que en cada momento han tenido sobre sí.

Qué sea la filosofía y cuál su origen y su cometido son cuestiones todas ellas de una importancia crucial. Más allá de la cuestión de los orígenes, muchas veces arrinconada y desprestigiada injustamente, el hecho de que no exista una respuesta unívoca a lo largo de la historia del pensamiento filosófico sobre la sustantividad de la especulación filosófica y su función es, en sí, más que una comprobación pesimista, un indicio de que probablemente la relatividad histórica ha sido y es la única certeza que cabe afirmar. No obstante, y nunca como carácter secundario, existen ciertas constantes 
que pueden subrayarse para no caer en el reduccionismo del extremismo escéptico. Las constantes filosóficas, sin duda alguna, radican más bien en la forma que en el contenido, más en cierta disposición que en los resultados obtenidos, más por el planteamiento de preguntas que por la consecución de respuestas. Con Karl Jaspers cabe afirmar que la filosofía es unterwegs, un ir de camino impulsado por la pregunta inquisitiva y la duda razonable, y, en su multiplicidad, el carácter filosófico no deja de ser ponderable: la filosofía, una y eterna, la philosophia perennis (Jaspers, 1953, 14).

Uno de los puntos en común entre la filosofía y la literatura estriba en que ambas poseen un origen eminentemente oral, al que le sucede una expresión escrita que transforma en buena medida su naturaleza primera. El proceso que va del trasvase del eje acústico-momentáneo al eje visivo-estable produce una modificación tanto en la sabiduría inicial de raigambre mística y mistérica como en la narración oral poético-épica ${ }^{1}$. Para Giorgio Colli, la escritura es precisamente el proceso que provoca el paso de la sabiduría y su logos como decir en la presencia a la filosofía y su objetividad de lo dicho recibido en la lectura, y por ello se produce un hiato por el que la interioridad se pierde (2000, p. 113). La explicación del paso subjetivo y unitario de la sabiduría esotérica al pensamiento abstracto, racional y discursivo la encuentra Colli en la dialéctica (ibid, p. 77). La dialéctica es la cumbre de la cultura clásica helénica y encuentra su desarrollo final en los Tópicos de Aristóteles. Y los grandes argumentadores dialécticos fueron Platón, Gorgias y Zenón. Frente a la sabiduría y al enigma, la dialéctica plantea un problema de marcado carácter agonístico. La despersonalización de la naturaleza que se ejecuta con el abandono de la "razón mitológica" hacia la conquista de la "razón filosófica" y la "razón científica" hermanada en los presocráticos implica, como consecuencia de la progresiva desaparición de los dioses mitológicos, la constante especulativa del agonismo humano. Así, por ejemplo, en el caso de la dialéctica, el agonismo queda representado en el planteamiento por parte del interrogador de las dos ramas de una contradicción; una vez que el interrogado toma parte por una de ellas, la labor del activo interrogador no será otra que la de tratar de destruirla mediante una reducción al absurdo deducida por el hilo argumentativo que el juego de preguntas y respuestas componen. La dialéctica, en puridad, es el resultado de la progresiva desdivinización del pensamiento inquisitivo sobre la sustancia del mundo y su teleología, así como, consecuentemente, el planteamiento humano de cuestiones relativas a la teoría del conocimiento. La religión y el mito eran las fundamentaciones principales del hombre en los orígenes.

Con los jonios el pensamiento filosófico se rebela contra el mito. En el caso de la religión, por ejemplo, Jenófanes y Heráclito critican el tratamiento que de las divinidades hace el mito, su antropomorfización y su reducción a lo fenoménico de sus representaciones icónicas, literarias o

\footnotetext{
1 “[...] en el tránsito del poema épico a la narrativa, en la que la novela es la forma clásica, hay que dar primacía previamente a la tradición oral, que permitió la difusión a través del tiempo de mitos, leyendas e historias tradicionales, si bien el anonimato que caracteriza los orígenes de este género con relación a la paternidad de las composiciones nos lleva a distinguir entre un productor real, su concreto autor, y un emisor eventual, su posible transmisor. Uno, creador, y otro, recreador, intentan influir sobre su auditorio mediante la enseñanza y/o el deleite, dualidad horaciana que resume la finalidad universal de la Poética clásica. A partir del siglo XIII, sin embargo, con el cambio de conciencia del autor, y, fundamentalmente, a partir del siglo XV, con el surgimiento de la imprenta, los textos narrativos, como otros tantos tipos de textos, llegarán a sus receptores a través del eje visivo-estable de la comunicación” (Chico Rico, 1987, pp. 113 y 114).
} 
escultóricas. La especulación filosófica de los jonios no puede aceptar la narración mítico-literaria porque cree que esta es tomada en su totalidad por los hombres como verdadera sin ser capaces de desentrañar lo que en esencia trata de transmitir, su verdad inherente. Así, Heráclito descubre en su crítica la misión simbólica de la religión (Nestle, 1987, p. 64).

Pero el proceso de escritura filosófica que los diálogos platónicos incoan no solo es deudor del método dialéctico, la retórica también ocupa un importante lugar. Para Colli, la retórica es una vulgarización de la dialéctica, a pesar de que surge con antelación e independencia de esta. Pero en realidad, no nos interesan tanto los juicios valorativos sobre la dialéctica y la retórica cuanto la opinión más interesante de que fue Gorgias quien impulsó la intervención de la escritura dentro del proceso retórico en principio eminentemente oral. La escritura retórica tenía una función técnica: los oradores se servían del discurso escrito como base para aprenderlo de memoria y sobre el cual trabajar su actio o pronuntiatio; y, según Colli, "Esa situación accidental de la retórica con relación a la escritura tuvo una influencia bastante destacada en la aparición de un nuevo género literario, la filosofía" (Colli, 2000, p. 109). Progresivamente, la escritura se fue despojando de su consideración como instrumento memorístico para ir adquiriendo libertad expresiva. Platón llamó filosofía a su literatura dialogada para diferenciarla de la anterior "sofía", sabiduría exenta de plasmación escrita y cifrada en la unidad subjetiva de raíces mistéricas y místicas que alcanzan la expresión en el enigma. Retórica y dialéctica, agonismo y genio expresivo, la filosofía se nutre en su nacimiento de todos estos elementos para configurarse como una expresión que desde entonces aparecerá ligada a la escritura literaria ${ }^{2}$.

En este ámbito de cosas no es extraña para la Teoría de la Literatura la reflexión sobre las relaciones entre literatura y filosofía, cuando ya en la Poética de Aristóteles encontramos un pasaje donde se reclama el carácter filosófico de las ficciones literarias:

[...] no es obra de un poeta el decir lo que ha sucedido, sino qué podría suceder, y lo que es posible según lo que es verosímil o necesario. Pues el historiador y el poeta no difieren por decir las cosas en verso o no, pues sería posible poner las obras de Heródoto en verso y no sería menos una historia en verso que sin él; sino que difieren en que uno dice lo que ha ocurrido y el otro qué podría ocurrir. Y por eso la poesía es más filosófica y noble que la historia, pues la poesía dice más bien las cosas generales y la historia las particulares (Aristóteles, 1984, p. 75).

Hay, por lo tanto, en el mundo antiguo un desplazamiento de la verdad del arte en tanto en cuanto dependiente de lo ritual al simulacro independizado de cualesquiera funciones mítico-religiosas y solo aquiescente a los valores laicos y cívicos. La poesía, la literatura, adquiere en el contexto del conjunto de artes una independencia formal que la irá alejando, al igual que al resto de las expresiones artísticas, del uso ritual y mítico para conseguir un valor intrínseco a partir de su forma. La mímesis, en este sentido y como afirma José Jiménez,

[...] expresa en su sentido más profundo la idea de "representación", a la vez dinámica o performativa y objetiva o material, la idea de producción de imágenes. En este punto, la comparación entre Grecia y Roma

\footnotetext{
2 "La 'filosofía' surge de una disposición retórica acompañada de un adiestramiento dialéctico, de un estímulo agonístico incierto sobre la dirección que tomar, de la primera aparición de una fractura interior en el hombre de pensamiento, en que se insinúa la ambición veleidosa al poder mundano, y, por último, de un talento artístico de alto nivel, que se descarga desviándose, tumultuoso y arrogante, hacia la invención de un nuevo género literario” (Colli, 2000, p. 119).
} 
resulta sumamente iluminadora. Los latinos tradujeron mímesis como imitatio, pero como hizo notar Erwin Panofsky la raíz semántica de imitatio es justamente la misma que la de imago (Jiménez, 2002, pp. 68-69).

II. La literatura ha tenido y sigue teniendo hoy en día la tarea de plantear las cuestiones fundamentales en un mundo en el que la especialización ha provocado una segmentación en la misma naturaleza del hombre y en su manera de comprender el mundo. La modernidad ha promocionado un espectacular progreso de la técnica debido a la revolución científica incoada, entre otros, por Galileo y Descartes, pero ha olvidado los aspectos existenciales más inherentes a la vida del hombre. Así, en relación con el avance científico solo cabe denunciar la inflación entre los descubrimientos casi siempre puestos en manos de los intereses productivos de la economía y su razón instrumental, y el quejumbroso deambular de todo lo relativo a lo que Husserl llamó die Lebenswelt.

Sin duda alguna, es ineludible subrayar la necesidad de la literatura como lugar desde el que reclamar el cambio con la fundamentación filosófica que los conceptos de realidad, existencia, modelo de mundo, libertad y posibilidad proporcionan. Así, por ejemplo, una de las corrientes filosóficas más críticas y conscientes de la situación, como es el desarrollado por la Escuela de Frankfurt, proclamó el arte como el lugar en donde aún reside la posibilidad. De ahí que no todo lo dado en la modernidad requiera su rechazo de raíz: en ella misma nace la conciencia de la necesidad del cambio; en ella misma podemos vislumbrar replanteamientos del ser desde ámbitos no velados por el interés de la razón productiva, porque, al devenir en mito la misma modernidad, en su interior nace la crítica de que otro modo de plantear la existencia es posible, una existencia que no quede atada a los criterios de la razón absolutista y destructora.

En esta actitud, cabe afirmar con Milan Kundera que, "si es cierto que la filosofía y las ciencias han olvidado el ser del hombre, aún más evidente resulta que con Cervantes se ha creado un gran arte europeo que no es otra cosa que la exploración de este ser olvidado" (Kundera, 2000, p. 15). La novela, en este caso referida por el checo, pero también las más arriesgadas obras artísticas, se ha ocupado en la modernidad de ese ámbito del que buena parte de la filosofía ha renunciado, influida, de un lado, por la especialización de las ciencias y convirtiéndose en mera propedéutica filosófica, y, de otro, por unos intereses sociales que inyectan de forma no siempre consciente desprestigio, silencio e inferioridad en la reflexión sobre el mundo de la vida o en las ciencias del espíritu.

Convengamos con Karl Jaspers en que el origen de la filosofía no es cuestión parangonable con su comienzo: el uno es el impulso hacia el saber, y el otro, el inicio histórico. El origen, en este sentido, resulta siempre parejo, hoy y en el tiempo de Platón, "la fuente de la que mana en todo tiempo el impulso que mueve a filosofar" (Jaspers, 1993, p. 15). La verdadera literatura, la que se plantea las grandes preguntas, coincide plenamente con el fin filosófico, pero utiliza otros medios expresivos -el lenguaje literario, el mito, la ficción, el símbolo, la metáfora, por decir algunas de las técnicas constantes de la prosa narrativa-, que, a su vez, pueden responder a un proceso de actualización artística de conceptos ya elaborados en la especulación filosófica. En otras ocasiones, y de un modo más original, la literatura plantea desde su forma expresivo-artística cuestiones que por su trascendencia 
merecen una especial atención. No hay filosofía ni literatura desde el dogma, y no serán tales por su renuncia a la duda y al asombro, orígenes del filosofar ${ }^{3}$ y de la creación artístico-literaria.

Milan Kundera compartiría estas afirmaciones sobre el rechazo del absolutismo como premisa para la escritura literaria y la especulación filosófica. Viene esto a colación para ejemplificar el alto designio que la literatura alcanza para el escritor checo desde su análisis del nacimiento de la novela moderna con la escritura cervantina del Quijote. A sus ojos, esa tradición cervantina se ha encargado de plantear las cuestiones relativas al ser que la filosofía, como analizó Martin Heidegger en Ser y Tiempo, ha olvidado en beneficio de las ciencias y de la técnica. Desde el planteamiento de que la novela nace en la modernidad y por ello posee en su naturaleza la relatividad y la ambigüedad de la nueva concepción del mundo, se sigue que se opone de raíz a cualquier "universo totalitario" y se revela como un avanzado método de conocimiento:

En efecto, todos los grandes temas existenciales que Heidegger analiza en Ser y Tiempo, y que a su juicio han sido dejados de lado por toda la filosofía europea anterior, fueron revelados, expuestos, iluminados por cuatro siglos de novela -cuatro siglos de reencarnación europea de la novela-. Uno tras otro, la novela ha descubierto por sus propios medios, por su propia lógica, los diferentes aspectos de la existencia: con los contemporáneos de Cervantes se pregunta qué es la aventura; con Samuel Richardson comienza a examinar "lo que sucede en el interior", a desvelar la vida secreta de los sentimientos; con Balzac descubre el arraigo del hombre en la Historia; con Flaubert explora la tierra hasta entonces incógnita de lo cotidiano; con Tolstoi se acerca a la intervención de lo irracional en las decisiones y comportamiento humanos. La novela sondea el tiempo: el inalcanzable momento presente con James Joyce. Se interroga con Thomas Mann sobre el papel de los mitos que, llegados del fondo de los tiempos, teledirigen nuestros pasos. Et caetera, et caetera (Kundera, 2000, p. 15).

Como se ve, la literatura puede reflexionar en su interior sobre asuntos propios de la filosofía. Desde el ámbito de la filosofía española se ha subrayado con determinación que el pensamiento español ha encontrado como forma para su expresión las más de las veces un estilo literario, a veces novelístico, otras dramático, cuando no poético. Si se lee con atención una de las magnas obras que sobre nuestra tradición existe, la Historia crítica del pensamiento español de José Luis Abellán, queda clara la importancia filosófica que poseen las obras de Calderón de la Barca, Quevedo, Cervantes, Unamuno y Antonio Machado, entre otros. La tendencia del hispanismo filosófico que reconoce en la literatura el ámbito desde el cual la filosofía española ha encontrado una óptima expresión tiene como origen la obra de Miguel de Unamuno Del sentimiento trágico de la vida. En esta el filósofo vasco reflexiona sobre su libro Vida de Don Quijote y Sancho y su atrevida relectura de Don Quijote de la Mancha de Cervantes. Unamuno es consciente de haber llevado a cabo una interpretación muy especial del clásico cervantino más allá de los rasgos canónicos de una hermenéutica académica. La hermenéutica que Unamuno yergue es la hermenéutica de la vida, una lectura de la obra literaria que rescate lo que en ella hay de vida lejos de la letra muerta de la erudición filológica. Así, se pregunta y se contesta el mismo Unamuno: “¿Qué me importa lo que Cervantes quiso o no quiso poner allí y lo que realmente puso? Lo vivo es lo que yo allí descubro, pusiéralo o no Cervantes, lo que yo allí pongo

\footnotetext{
${ }^{3}$ Según Karl Jaspers, el origen del filosofar es múltiple: "Del asombro sale la pregunta y el conocimiento, de la duda acerca de lo conocido el examen crítico y la clara certeza, de la conmoción del hombre y de la conciencia de estar perdido la cuestión de sí propio" (Jaspers, 1993, p. 15).
} 

Mauro Jiménez

y sobrepongo y sotopongo, y lo que ponemos allí todos. Quise rastrear nuestra filosofía" (Unamuno, 2000 , pp. 310 y 311). Unamuno pone punto y final a su párrafo hablando, sin embargo, de filosofía. De este modo da un importante salto cualitativo, ya que de una simple interpretación debemos pasar a hablar de una hermenéutica que desvela en los textos literarios la filosofía de la cultura que albergan en su interior. Y así aparece consignado en unas importantísimas líneas en torno a la proteica relación entre literatura y filosofía, según Unamuno:

Pues abrigo cada vez más la convicción de que nuestra filosofía, la filosofía española, está líquida y difusa en nuestra literatura, en nuestra vida, en nuestra acción, en nuestra mística, sobre todo, y no en sistemas filosóficos. Es concreta. ¿Y es que acaso no hay en Goethe, verbigracia, tanto o más filosofía que en Hegel? Las coplas de Jorge Manrique, el Romancero, el Quijote, La vida es sueño, la Subida al Monte Carmelo, implican una intuición del mundo y un concepto de la vida Weltanschauung und Lebensansicht. Filosofía esta nuestra que era difícil de formularse en esa segunda mitad del siglo XIX, época afilosófica, positivista, tecnicista, de pura historia y de ciencias naturales, época en el fondo materialista y pesimista (Unamuno, 2000, p. 311).

III. La creación poética, según la exposición que de ella realiza Aristóteles, lo he apuntado atrás, sitúa el campo de su acción en un terreno al que la filosofía difícilmente puede otorgar un valor positivo o negativo de verdad o mentira en sentido fáctico. La realidad efectiva, en este sentido, no opera en la literatura más que como modelo sobre el que realizar una imitación más o menos verosímil. Sin embargo, y a pesar de su carencia ontológica efectiva, la literatura posee en su interior un alcance filosófico que reside en la capacidad expresiva e imaginativa del hombre. Como dice Antonio García Berrio, la literatura permite al hombre completar su idea de la realidad más allá de la simple experiencia histórica ${ }^{4}$. Para Aristóteles, es precisamente la capacidad mimética el rasgo que convierte a la creación literaria en una actividad cercana a la filosofía. Aristóteles, que fue sobre todo un gran filósofo de la naturaleza y que esgrimió con antelación a Euclides el ideal deductivo del saber científico, no podía dejar de atisbar cómo en la literatura el ámbito sobre el que establecer hipótesis crecía considerablemente. Entonces, sobre la base de unos hechos efectivos aceptados por la razón como ciertos, la imaginación genera una expansión verosímil creando una acción ficcional que realizan unos personajes. Sin embargo, cuando marcamos una diferencia entre el ámbito de la filosofía y el de la literatura, hablamos fundamentalmente de la utilización de un lenguaje y de un método distinto con los que desentrañar la realidad. Es cierto que tanto la filosofía como la literatura tienen como principal instrumento la palabra; sin embargo, esta es utilizada de un modo diverso en un ensayo filosófico, en

\footnotetext{
${ }^{4}$ Señala García Berrio: “[...] la Poética es para Aristóteles una facultad complementaria del conocimiento filosófico. La poesía supone la posibilidad que el hombre tiene de duplicar la realidad, creando a través de la imitación o mímesis un mundo ficcional que él mismo estructura y gobierna. El principio de verdad, que regula la experiencia de los acontecimientos históricos y reales, restringe enormemente las posibilidades humanas de previsión ética e imaginativa. Mediante la invención poética, regida por las convenciones de la verosimilitud, el hombre amplía y enriquece definitivamente su experiencia; sitúa los personajes y los acontecimientos en todos los supuestos posibles y extremos, a los que no se extiende la articulación delimitada de su desarrollo real. Por eso decía Aristóteles que la poesía es más universal y filosófica que la historia; porque esta narra únicamente "lo sucedido", mientras que aquélla "lo que hubiera podido suceder, según lo verosímil y necesario" (51ª 37-38)” (García Berrio, 1994, p. 27).
} 
un tratado de ética, en un discurso de filosofía analítica que en una narración, en una pieza dramática o en un poemario.

No obstante, acusada de falseamiento, mentira y engaño, la literatura también ha recibido la diatriba incoada por Platón en su República, donde se destaca a los políticos y a los filósofos y se coloca en un segundo plano a los poetas imitadores. Hay que marcar la adjetivación platónica sobre los poetas que rechaza, ya que aquellos poetas cuya voz es movida por la inspiración no son atacados desde la filosofía de Platón. En realidad, la cuestión está estrechamente conectada con su teoría del conocimiento; o, de otro modo, no es posible comprender la oposición de Platón hacia los poetas si no ponemos en relación la ficción literaria con su epistemología esencialista. Aquellos poetas que, según el filósofo, imitan atraen y persuaden gracias al uso que del lenguaje llevan a cabo. De este modo se refiere al acierto expresivo, esto es, al dominio de la retórica literaria. Sin embargo, aquellos textos que convencen por su parecido con la realidad no muestran la verdad de esta, según Platón, sino una apariencia de verdad. Así, los poetas hacen pasar por verdad lo que es imitación:

[...] podemos decir que el poeta colorea cada una de las artes con palabras y frases, aunque él mismo solo está versado en el imitar, de modo que a los que juzgan solo en base a palabras les parezca que se expresa muy bien, cuando, con el debido metro, ritmo y armonía, habla acerca del arte de la zapatería o acerca del arte del militar o respecto de cualquier otro; tan poderoso es el hechizo que producen estas cosas (Platón, 2000, p. 462, 598b).

Consecuente con la lógica seguida en su argumentación, Platón estima necesario el ataque y el repudio a los poetas de la República ideal, puesto que, además de hacer pasar por verdadero sus imitaciones dirigen sus dardos hacia la diana de las pasiones del alma:

Por lo tanto, es justo que lo ataquemos y que lo pongamos como correlato del pintor; pues se le asemeja en que produce cosas inferiores en relación con la verdad, y también se le parece en cuanto trata con la parte inferior del alma y no con la mejor. Y así también es en justicia que no lo admitiremos en un Estado que vaya a ser bien legislado, porque despierta a dicha parte del alma, la alimenta y fortalece, mientras echa a perder a la parte racional, tal como el que hace prevalecer políticamente a los malvados y les entrega el Estado, haciendo sucumbir a los más distinguidos. Del mismo modo diremos que el poeta imitativo implanta en el alma particular de cada uno un mal gobierno, congraciándose con la parte insensata de ella, que no diferencia lo mayor de lo menor y que considera a las mismas cosas tanto grandes como pequeñas, que fabrica imágenes y se mantiene a gran distancia de la verdad (Platón, 2000, pp. 473 y 474, 605b-c).

Pese a que secularmente se ha tendido a identificar la literatura con el repliegue de la vida bajo la acusadora óptica platónica, es fortuna atisbar cómo cabe esa otra tradición aristotélica que pondera la ficción literaria como posibilitadora de sentido y también como creadora de ficciones modelizantes y modelos de mundos (Asensi Pérez, 2011, p. 17). A lo anterior habría que añadir todavía el alcance del ensayo de Mario Vargas Llosa sobre el poder de la ficción en relación con la verdad y la filosofía. En El poder de las mentiras, aborda ensayísticamente al alcance cognoscitivo de las narraciones literarias. No hay que perder de vista el hecho de que a lo largo de la historia algunas obras literarias han sido perseguidas desde instancias religiosas o políticas. Cuando esto sucede, cabe preguntarse cuál es el motivo último, el peligro que el poder halla en la literatura. El escritor peruano indica que los inquisidores españoles prohibieron en las colonias hispanoamericanas la lectura de novelas porque las 

Mauro Jiménez

creían perjudiciales para la salud moral de los indios, que podían sentirse engañados por las mentiras literarias. De ahí que la primera novela publicada en la América española solo apareciera una vez acontecida la independencia, concretamente en México en 1816. Este tipo de prohibiciones nos ponen en la pista del poder de la ficción literaria.

La ficción literaria se ocupa de una realidad verosímil o inverosímil, según sea el grado de respeto a las leyes que rigen el mundo fenoménico, cuyo ámbito de acción, en principio, queda circunscrito al mundo imaginario sostenido mediante la narración (Albaladejo, 2016, pp. 49-50). Desde este punto de vista es evidente que las novelas son mentira, es decir, plantean unos hechos que no han acontecido tal y como se narran, pues de lo contrario estaríamos ante un libro de historia. Para Vargas Llosa, como para Sartre y Camus, la literatura dista mucho de ser un mero pasatiempo. Toda creación literaria que se precie nace de una insatisfacción, de un deseo, de una voluntad que encuentra frente a sí un mundo que quiere modificar en la medida de lo posible:

En efecto, las novelas mienten -no pueden hacer otra cosa- pero esa es solo una parte de la historia. La otra es que, mintiendo, expresan una curiosa verdad, que solo puede expresarse disimulada y encubierta, disfrazada de lo que no es. Dicho así, esto tiene el semblante de un galimatías. Pero, en realidad, se trata de algo muy sencillo. Los hombres no están contentos con su suerte y casi todos -ricos o pobres, geniales o mediocres, célebres u oscuros- quisieran una vida distinta de la que viven. Para aplacar-tramposamente- ese apetito nacieron las ficciones. Ellas se escriben y se leen para que los seres humanos tengan las vidas que no se resignan a no tener. En el embrión de toda novela bulle una inconformidad, late un deseo (Vargas Llosa, 1996, p. 6).

Un modo más exhaustivo y analítico que el utilizado por el novelista peruano para revelar la verdad que el lector halla en la literatura y el modo en que esta influye en él se encuentra en la observación del poder perlocutivo de la palabra ficcional. Desde este punto de vista, quienes buscan la diferenciación entre filosofía y literatura apelan a la epistemología y a la teoría de los actos de habla ${ }^{5}$. Según esta visión, que marcaría una diferencia entre la relación proteica que nos ocupa, aunque para la literatura el acto locutivo y el ilocutivo son importantes lo es aún más el perlocutivo, puesto que su objetivo sería la influencia en el receptor de algún modo gracias a la perlocución (Grimaltos, 2008, pp. 126-127). Esto quiere decir que las respuestas que busca la literatura en el lector no son transparentes, esto es, que la intención perlocutiva del autor se consigue no tanto al decir, sino más bien al mostrar.

Hay, por lo tanto, desde el ámbito de la filosofía más cercana a la ciencia una voluntad de separar su campo del literario a partir de la distinción entre discursos que se diferencian formalmente y pragmáticamente. Pero quizá la cuestión sobre la relación entre la literatura y la filosofía haya que situarla en el problema del conocimiento, en el sentido de qué es aquello que la literatura nos puede enseñar y si esta enseñanza se acerca o bordea los límites de lo filosófico. Tradicionalmente la filosofía ha estado asociada a la idea de verdad, de modo que si pretendemos unir filosofía y literatura, el

\footnotetext{
${ }^{5}$ Estos tres actos, que no son actos diferentes, son expuestos así por Francisco Chico Rico: "Estos tres tipos de actos no constituyen en modo alguno actos diferentes, sino tres subactividades analíticamente discernibles en cada ejecución lingüística: en verdad, realizar un acto locutivo, es decir, emitir una expresión correcta con un significado determinado, es, en general, realizar un acto ilocutivo, ejecutar una acción, acto al cual corresponde, por el hecho de haber llevado a cabo la mencionada expresión, en los casos de comunicación positiva, un acto perlocutivo definido, tendente a la satisfacción de las necesidades que motivaron la realización por parte del productor de aquel acto de habla” (Chico Rico, 1987, p. 121).
} 
concepto de verdad canónicamente convocado a la hora de hablar de filosofía debe variar hacia un marco epistémico en donde sea posible una experiencia de la verdad desde el mundo de la vida, en el sentido señalado por Enrique Lynch:

[...] el proyecto de llevar la filosofía a la vida era algo más que una consigna vitalista opuesta a la desentrañada Razón de los ilustrados: implicaba tácitamente que la filosofía aceptaba ser reducida a un proyecto de saber en alguna medida equiparable con esa sabiduría discreta que la literatura compone a partir de los acontecimientos mundanos. Recordemos que la verdad fue desde el origen de la filosofía un signo de identidad del discurso filosófico y que, en cambio, la experiencia individual o las vicisitudes de los pueblos -esto es, la vida y las ilusiones que esta conlleva- eran materia de relatos, narraciones de la historia y la literatura, un terreno en el que la verdad queda de hecho suspendida. Llevar la filosofía a reencontrarse con la vida, hacerla alegre o beatífica, conllevaba necesariamente abandonar el rígido patrón de la verdad (Lynch, 2006, p. 29).

Pero si, como piensa Wittgenstein, "una buena metáfora refresca el entendimiento" (Wittgenstein, 2013: 33), la buena literatura sería la mejor oxigenación para el pensamiento. En este sentido, es habitual la generalizada asimilación entre literatura y metáfora, cuando también esta desempeña una función capital en la filosofía. Hay un pasaje de la Retórica de Aristóteles sobre la metáfora que es apenas frecuentado y que muestra esta otra vía para la conexión entre literatura y filosofía que merece la pena recordar: "Deben construirse las metáforas, como antes se dijo [sobre un pasaje de la Iliada], de cosas apropiadas, pero no evidentes, igual que ocurre en la filosofía, donde advertir la similitud incluso en cosas que difieren considerablemente es propio de una mente aguda" (Aristóteles, 2007, p. 280). Esta senda que transita del espacio literario al espacio filosófico y que vincula la escritura con la retórica y con la estética para alcanzar ecos éticos y políticos en la vida del hombre fue, de hecho, lo que pretendió dinamitar Nietzsche con su crítica metafísica desde una base metafórica que deseaba desvelar. Para el filósofo del martillo, uno de los problemas reside en el olvido de que en sí el lenguaje es pura metáfora, por lo que el concepto científico y el filosófico es una estructura tan metafórica como la que descubrimos en el lenguaje literario: "Creemos saber algo de las cosas mismas cuando hablamos de árboles, colores, nieve y flores y no poseemos, sin embargo, más que metáforas de las cosas, que no corresponden en absoluto a las esencialidades originarias" (Nietzsche, 2011, p. 612).

IV. Y, por fin, sirvan todas las anteriores consideraciones hasta aquí planteadas como una presentación ensayística para este dosier, esto es, como un atrio para la vasta morada en la que conviven metamorfoseándose continuamente la literatura y la filosofía. Como se verá en los diez textos que siguen a estas líneas, no solo no hay una vía única de acceso a esta morada inmensa, sino que en su interior hay quienes construyen tabiques para discriminar lo literario de lo filosófico, otros perseveran en la difuminación de las diferencias, algunos deambulan fructíferamente por sus estancias sin parar mientes en los rótulos de cada umbral, pero todos coinciden en la importancia de esta relación proteica en un mundo en el que cada vez más se pretende silenciar el poder liberador de la literatura y de la filosofía para las servidumbres de todo signo. Con expresión de agradecimiento a los directores 
de la revista Tropelías, así como con manifestación de gratitud para los autores por sus destacadas contribuciones, espero, lector, que atisbes razones suficientes en este monográfico para que su lectura merezca la pena. Vale.

\section{Referencias bibliográficas}

Albaladejo, Tomás (2016). Teoría de la Literatura y Estética. Laocoonte. Revista de Estética y Teoría de las Artes, 3, 49-58.

Aristóteles, Horacio y Boileau (1984). Poéticas, ed. de Aníbal González Pérez. Madrid: Taurus. ARISTÓTELES (2007). Retórica, trad. de Alberto Bernabé. Madrid: Alianza.

ASENSI PÉREZ, Manuel (2011). Crítica y sabotaje. Barcelona: Anthropos.

CHICO Rico, Francisco (1987). Pragmática y construcción literaria. Alicante: Universidad de Alicante.

Colli, Giorgio (2000). El nacimiento de la filosofía, trad. de Carlos Manzano. Barcelona: Tusquets. GARCÍA BERRIO, Antonio (1994). Teoría de la Literatura (La construcción del significado poético). Madrid: Cátedra, $2^{\mathrm{a}}$ ed. revisada y ampliada.

GRAVES, Robert (2009). Los mitos griegos, trad. de Esther Gómez. Barcelona: RBA.

GRIMALtos, Tobies (2008). Dues nissagues mil-lenàries. Filosofia i literatura. L'espill, 29, 124-132.

JASPERS, Karl (1993). La filosofía desde el punto de vista de la existencia, trad. de José Gaos. Madrid: FCE.

JiMÉNEZ, José (2002). Teoría del arte. Madrid: Tecnos/Alianza.

KUnDERA, Milan (2000). El arte de la novela, trad. de Fernando de Valenzuela y María Victoria Villaverde. Barcelona: Tusquets.

LYNCH, Enrique (2006). Filosofía y/o literatura. Identidad y/o diferencia. Pamplona: Universidad Pública de Navarra.

Machado, Antonio (2003). Juan de Mairena I, ed. de Antonio Fernández. Madrid: Cátedra.

NeSTLE, Wilhelm (1987). Historia del espíritu griego: desde Homero hasta Luciano, Barcelona, trad. de Manuel Sacristán. Barcelona: Ariel.

NIETZSCHE, Friedrich (2011). Sobre verdad y mentira en sentido extramoral. Obras completas. Volumen I, ed. de Diego Sánchez Meca. Madrid: Tecnos.

Platón (2000). República, trad. de Conrado Eggers Lan. Madrid: Gredos.

SÁNCHEZ MECA, Diego (2016). Conceptos en imágenes. La expresión literaria de las ideas. Madrid: Avarigani.

UnAmuno, Miguel de (2000). Del sentimiento trágico de la vida. Madrid: Alianza.

VARGAs LlosA, Mario (1990). La verdad de las mentiras. Ensayos sobre literatura. Barcelona: Seix Barral.

Wittgenstein, Ludwig. (2013). Aforismos. Cultura y valor, trad. de Elsa Cecilia Frost. Madrid: Austral. 